Alma Mater Studiorum - Università di Bologna DEPARTMENT OF ECONOMICS

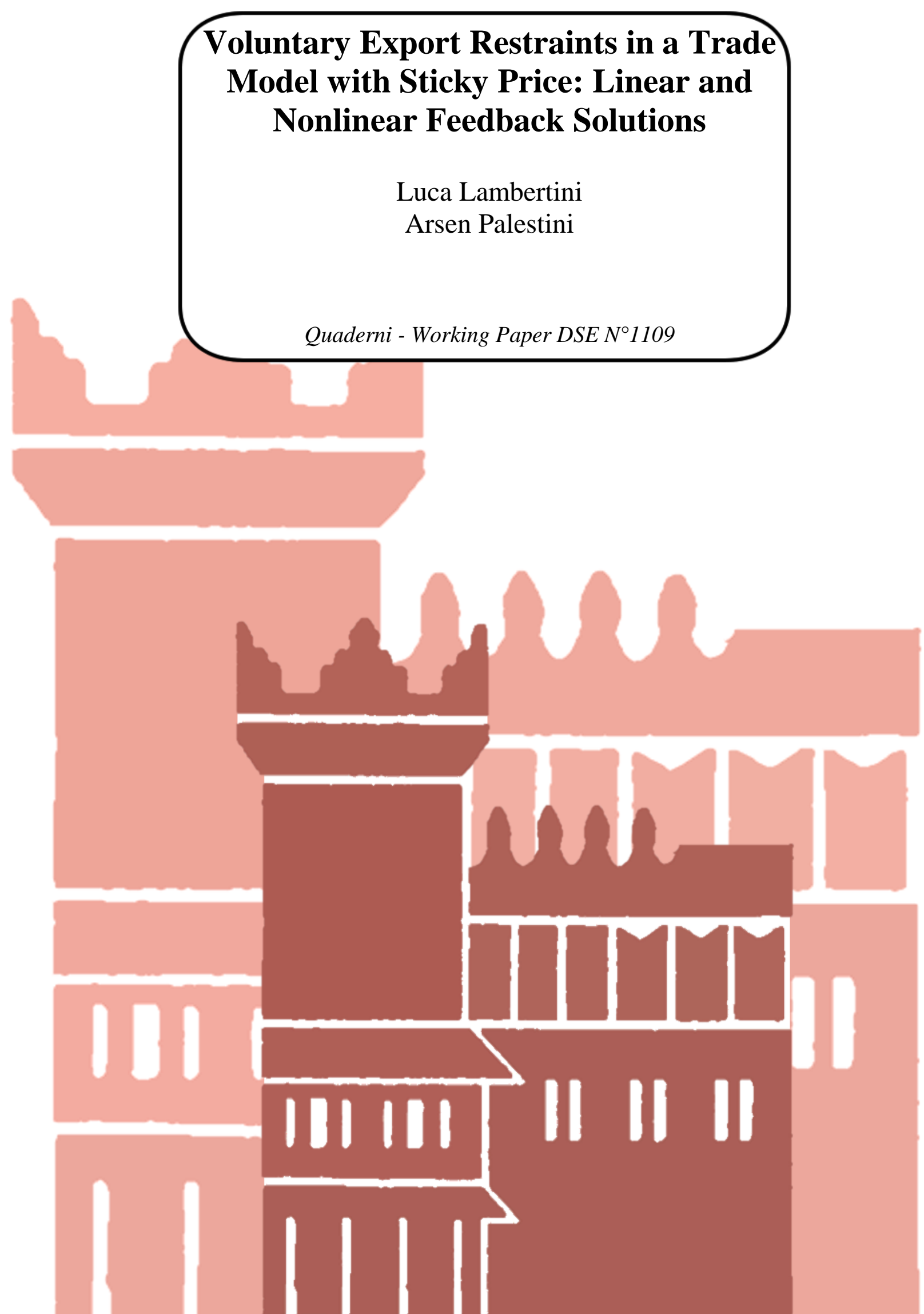




\title{
Voluntary Export Restraints in a Trade Model with Sticky Price: Linear and Nonlinear Feedback Solutions
}

\author{
Luca Lambertini ${ }^{\#}$ and Arsen Palestini ${ }^{\S}$ \\ \# Department of Economics, University of Bologna \\ Strada Maggiore 45, 40125 Bologna, Italy; luca.lambertini@unibo.it \\ $\S$ MEMOTEF, University of Rome "La Sapienza"
}

Via del Castro Laurenziano 9, 00161 Rome, Italy; arsen.palestini@uniroma1.it

October 19, 2017

\begin{abstract}
We revisit the adoption of voluntary export restraints (VERS) in the differential Cournot game with sticky price and intraindustry trade by Dockner and Haug (1991). The analysis relies on linear and nonlinear feedback strategies, to encompass the special cases considered in Fujiwara (2010) and to show that a VER may arise in correspondence of any free trade equilibrium generated by feedback information such that competition is at least as strong as under open-loop rules. This result can be interpreted in the light of the dynamic formulation of conjectural variations due to Dockner (1992).
\end{abstract}

JEL Codes: C73, D43, F12, L13

Keywords: differential games; intraindustry trade; VER; conjectural variations 


\section{Introduction}

The impact and desirability of output restrictions has been lively discussed in the literature on intraindustry trade, from two main standpoints. The first, at least since Bhagwati (1965) and Shibata (1968), considers the equivalence between tariffs and quotas (see also Itoh and Ono, 1982, 1984; and Hwang and Mai, 1988). The second is instead concerned with the possible adoption of a restrictive practice by exporting firms, in the form of voluntary export restraints (VERs). The initial results in this vein date back to Harris (1985) and Mai and Hwang (1988), establishing that VERs can be observed at equilibrium if and only if the initial free trade equilibrium is more competitive than the Cournot equilibrium (hence, typically, VERs should be observed under price competition). Indeed, Mai and Hwang (1988) find that the VER is irrelevant, as its adoption leads to exactly the same industry output as under free trade.

These authors, as well as a number of others (Eaton and Grossman, 1986; Krishna, 1989; Bjorksten, 1994; and Suzumura and Ishikawa, 1997, among others) use static models, in which the kind (and intensity) of market competition is characterised through the instrument of conjectural variations (Bresnahan, 1981; Kamien and Schwartz, 1983). The limited ability of conjectural variations in capturing the dynamic nature of competition and therefore also firm's incentives to adopt unilateral restrictions induces Dockner and Haug (1991) to investigate anew the issue of VERs' adoption in a differential Cournot game with sticky prices à la Simaan and Takayama (1978) and Fershtman and Kamien (1987). Dockner and Haug (1991) confine their attention to the limit game in which firms use linear feedback strategies and the speed of price adjustment is infinitely high, to prove that, in such a case, the VER is indeed spontaneously adopted by the exporting firm, as it induces an output restriction by the domestic firm. As a result, both firms' profits increase as compared to the free trade equilibrium. Hence, in contrast with Mai and Hwang (1988), Dockner and Haug (1991) show, although in a single

case, that VERs can be observed under Cournot competition if dynamics (in 
this case, price dynamics) is accounted for. A qualitative appraisal of their result can be spelled out as follows. The spontaneous adoption of VERs by exporting firms requires the absence of precommitments (which is embodied in their analysis of the limit game under linear feedback rules), while it cannot arise when commitment is called for, to sustain the open-loop solution.

A partial extension of their analysis is in Fujiwara (2010), accounting for the linear feedback solution for any speed of price adjustment and the special case in which the continuum of nonlinear feedback strategies collapses onto the tangency solution. Relying on these two cases and the open-loop one, Fujiwara (2010) shows that the VER can be observed at equilibrium under the linear feedback solution, while this cannot happen in correspondence of the degenerate nonlinear feedback equilibrium; additionally, the VER has no impact at all on relevant magnitudes at the steady state reached under open-loop information.

We revisit the model using linear and nonlinear feedback strategies, with no restrictions on the speed of price adjustment, to obtain the following results. First, the open-loop steady state equilibrium can be attained using a nonlinear feedback strategy. Second, the degenerate nonlinear feedback equilibrium corresponding to the tangency point between the highest isocline of either firm and the steady state locus divides the set of steady states generated by feedback rules into two subsets, the first including all stable equilibria (from that yielded by the stable linear strategy to the tangency point), the second including unstable ones (from the tangency point to the steady state reached along the unstable linear strategy). Third, the first of these two sets is further partitioned into two parts by the open-loop steady state, produced by a specific nonlinear strategy, which delimits the portion of stable equilibria in correspondence of which the foreign firm has a strict incentive to spontaneously adopt the VER. Since the open-loop equilibrium can be reproduced through nonlinear feedback strategies, the interpretation of the VER in terms of precommitment or the lack thereof (Fujiwara, 2010, pp. 101-102) may be reformulated in terms of the intensity of competition 
under the full spectrum of stable feedback strategies: any initial free trade equilibrium generated by feedback rules at least as competitive as the openloop ones is bound to induce the adoption of the VER; the opposite holds instead for feedback equilibria more collusive than the open-loop one. This interpretation is in line with Dockner's (1992) analysis of dynamic conjectural variations, whose sign signals the emergence of an equilibrium which is bound to be more (respectively, less) competitive than the open-loop (or, in the limit, the static) one, when the conjectural variation is negative (positive).

The remainder of the paper is structured as follows. The model is laid out in section 2. Section 3 describes the continuum of symmetric feedback equilibria under free trade. The analysis of the foreign firm's incentive VER and its consequences on equilibrium magnitudes is in section 4 . Concluding remarks are in section 5 .

\section{The setup}

As in Dockner and Haug (1991), consider a two-country world in which countries are labelled as $h$ (home) and $f$ (foreign). A single firm is based in each country, and has an analogous index. Firm $f$ exports to country $h$ and competes against the local firm à la Cournot, in a duopoly existing over $t \in[0, \infty)$. Market price evolves according to

$$
\dot{p}(t)=s[\widehat{p}(t)-p(t)]
$$

where $\widehat{p}(t)=a-q_{1}(t)-q_{2}(t)$ defines the 'notional' inverse demand function and parameter $s \in[0, \infty)$ measures the speed of price adjustment (and therefore is an inverse measure of price stickiness). Transportation costs are assumed away. Hence, the instantaneous profit function of firm $i=f, h$ is

$$
\pi_{i}(t)=\left[p(t)-c-\frac{q_{i}(t)}{2}\right] q_{i}(t)
$$

and the same firm $i$ must therefore

$$
\max _{q_{i}(t)} \Pi_{i}=\int_{0}^{\infty}\left[p(t)-c-\frac{q_{i}(t)}{2}\right] q_{i}(t) e^{-\rho t} d t
$$


subject to the state equation (1) and the initial condition $p(0)=p_{0}>0$. The discount rate $\rho>0$ is common to both firms and time-invariant. Hence, the model is initially exactly the same as in Simaan and Takayama (1978) and Fershtman and Kamien (1987), but is interpreted as a description of an intraindustry trade scenario with homogeneous goods. Throughout the ensuing analysis, firms are assumed to operate under feedback rules, either linear or nonlinear, although the open-loop solution of the free trade case will also play a crucial role.

\section{Free trade}

The open-loop and linear feedback solutions of the free trade game can be quickly dealt with, as they replicate those appearing in Fershtman and Kamien (1987). Under open-loop information, the steady state levels of market price and individual output are

$$
\left\{\begin{array}{l}
p^{O L}=\frac{a(2 s+\rho)+2 c(s+\rho)}{4 s+3 \rho}>c \\
q^{O L}=\frac{(a-c)(s+\rho)}{4 s+3 \rho}
\end{array}\right.
$$

with

$$
\begin{aligned}
& \lim _{\rho \rightarrow 0} q^{O L}=\lim _{s \rightarrow \infty} q^{O L}=\frac{a-c}{4}=q^{C N} \\
& \lim _{\rho \rightarrow \infty} q^{O L}=\lim _{s \rightarrow 0} q^{O L}=\frac{a-c}{3}=q^{p c}
\end{aligned}
$$

The limits appearing in (5) - together with the analogous limits of $p^{O L}$, omitted for brevity - show that the, if either discounting or price stickiness is absent, open-loop steady state replicates the static Cournot-Nash outcome; while if either discounting or price stickiness is infinitely high, then the open-loop equilibrium collapses onto the perfectly competitive outcome. While Dockner and Haug (1991) focus their analysis to the limit game where $s \rightarrow \infty$, here we shall outline the properties of feedback equilibria for any admissible value of $s$. 
The linear feedback solution can be characterised following the same method used in Tsutsui and Mino (1990) and Rowat (2007). ${ }^{1}$ Firm $i$ must solve the following HJB equation (henceforth, we will omit the time argument):

$$
\rho V_{i}(p)=\max _{q_{i}}\left\{\left(p-c-\frac{q_{i}}{2}\right) q_{i}+V_{i}^{\prime}(p) s(\widehat{p}-p)\right\}
$$

where $V_{i}(p)$ is the value function and $V_{i}^{\prime}(p)=\frac{\partial V_{i}(p)}{\partial p}$. The first order condition can be solved w.r.t. the partial derivative of the value function:

$$
p-c-q_{i}-s V_{i}^{\prime}(p)=0 \quad \Longrightarrow \quad V_{i}^{\prime}(p)=\frac{p-c-q_{i}}{s} .
$$

Plugging this expression into (6), imposing symmetry and rearranging the HJB equation, one obtains

$$
V(p)=\frac{3 q^{2}(p)-2 p^{2}+2 a[p-q(p)-c]+2 c[p+q(p)]}{2 \rho}
$$

where individual output appears as a function of price. Differentiating (8) w.r.t. $p$, we have

$$
V^{\prime}(p)=\frac{a-c+2 p-[a-c-3 q(p)] q^{\prime}(p)}{\rho}
$$

where we can use the expression (7) for $V^{\prime}(p)$ so as to rewrite (9) as follows:

$$
q^{\prime}(p)=\frac{a s+c(s+\rho)+\rho q(p)-p(2 s+\rho)}{s[a-c-3 q(p)]}
$$

Before proceeding, it is worth noting that (10) implies that $q^{\prime}(p)=0$ at

$$
q_{0}(p)=\frac{p(2 s+\rho)-a s-c(s+\rho)}{\rho}
$$

and $q^{\prime}(p) \rightarrow \pm \infty$ as

$$
q(p) \rightarrow q_{\infty}=\frac{a-c}{3}=q^{p c}
$$

\footnotetext{
${ }^{1}$ See also Shimomura (1991), Dockner and Long (1993), Fujiwara (2008), Lambertini and Mantovani (2014, 2016) and Lambertini (2016), among others.
} 
Now, in view of the linear-quadratic form of the game, we may stipulate a linear form for the symmetric control variable, whereby $q(p)=\alpha p+\beta$, in such a way that (10) becomes

$$
\frac{s[a-c-3(\alpha p+\beta)] \alpha-[a s+c(s+\rho)+\rho q(p)-p(2 s+\rho)]}{s[a-c-3(\alpha p+\beta)]}=0
$$

whose numerator is nil (provided the denominator is not) in correspondence of the pairs $(\alpha, \beta)$ solving the following system:

$$
\left\{\begin{array}{l}
3 s \alpha^{2}+\rho \alpha-2 s-\rho=0 \\
(3 s \alpha+\rho) \beta+a(1-\alpha) s+c[(1+\alpha) s+\rho]=0
\end{array}\right.
$$

i.e.,

$$
\begin{gathered}
\beta=-\frac{a(1-\alpha) s+c[(1+\alpha) s+\rho]}{3 s \alpha+\rho} \\
\alpha_{ \pm}=\frac{-\rho \pm \sqrt{(6 s+\rho)^{2}-12 s^{2}}}{6 s}
\end{gathered}
$$

so that $q^{L F}\left(\alpha_{+}\right)$is increasing in $p$, while $q^{L F}\left(\alpha_{-}\right)$is decreasing in $p$. Using the two alternative expressions, the coordinates of the corresponding steady state points are

$$
\left\{\begin{array}{l}
q_{s s}^{L F}\left(\alpha_{+}\right)=\frac{(a-c)\left[6 s+5 \rho+\sqrt{(6 s+\rho)^{2}-12 s^{2}}\right]}{3\left[8 s+5 \rho+\sqrt{(6 s+\rho)^{2}-12 s^{2}}\right]} \\
p^{L F}\left(\alpha_{+}\right)=a-2 q^{L F}\left(\alpha_{+}\right)
\end{array}\right.
$$

and

$$
\left\{\begin{array}{l}
q_{s s}^{L F}\left(\alpha_{-}\right)=\frac{(a-c)\left[6 s+5 \rho-\sqrt{(6 s+\rho)^{2}-12 s^{2}}\right]}{3\left[8 s+5 \rho-\sqrt{(6 s+\rho)^{2}-12 s^{2}}\right]} \\
p^{L F}\left(\alpha_{-}\right)=a-2 q^{L F}\left(\alpha_{-}\right)
\end{array}\right.
$$

There remains to characterise the continuum of nonlinear feedback solutions. Without replicating the construction of the differential equation 
which generates the infinitely many nonlinear solutions, which is illustrated in Tsutsui and Mino (1990), we confine ourselves to stress its basic features and present the resulting picture in the state-control space. The continuum is partitioned into two subsets of stable and unstable solutions by the tangency point between a specific isocline and the steady state locus $\dot{p}=0$, i.e., $q^{s s}=(a-p) / 2$, whose slope is $\frac{\partial q^{s s}}{\partial p}=-1 / 2$.

This implies that such a point is identified by $q^{\prime}(p)=-1 / 2$ or, using (10) with $q(p)=q^{s s}$, by

$$
\frac{\rho}{s}+\frac{3 a+2 c-5 p}{2(a+2 c-3 p)}=0 \Longleftrightarrow p^{T}=\frac{2 \rho(a+2 c)+s(3 a+2 c)}{5 s+6 \rho}
$$

and the corresponding output

$$
q^{T}=\frac{a-p^{T}}{2}=\frac{(a-c)(s+2 \rho)}{5 s+6 \rho}
$$

Note that

$$
\lim _{\rho \rightarrow 0} q^{T}=\lim _{s \rightarrow \infty} q^{T}=\frac{a-c}{5}
$$

which is the output each firm would produce in the static maximization of joint profits (i.e., the static cartel solution). In general, as the speed of price adjustment increases or discounting decreases, the tangency point approaches the static fully collusive outcome.

For any positive and finite values of $s$ and $\rho$,

$$
q_{s s}^{L F}\left(\alpha_{+}\right)>q^{O L}>q^{T}>q_{s s}^{L F}\left(\alpha_{-}\right)
$$

while clearly the opposite sequence holds for the corresponding prices.

The stability properties of the state-control system are described in Figure 1, which shows trajectories in the quantity-price quadrant, where both linear feedback strategies are depicted. The stable linear feedback strategy is $q^{L F}\left(\alpha_{+}\right)$, producing the stable steady state at $A$. The other steady state point at $B$ is unstable instead. The point $T$ is unstable as well, as is indicated by the arrows along the isocline tangent to the steady state locus. 
However, the upper isocline intersecting twice the stability locus tells that any intersection between the steady state locus and one among the infinitely many nonlinear feedback strategies at a point belonging to the segment $A T$ is indeed stable (while the opposite applies to any intersection in the segment $T B)$.

Figure 1 The phase diagram under free trade

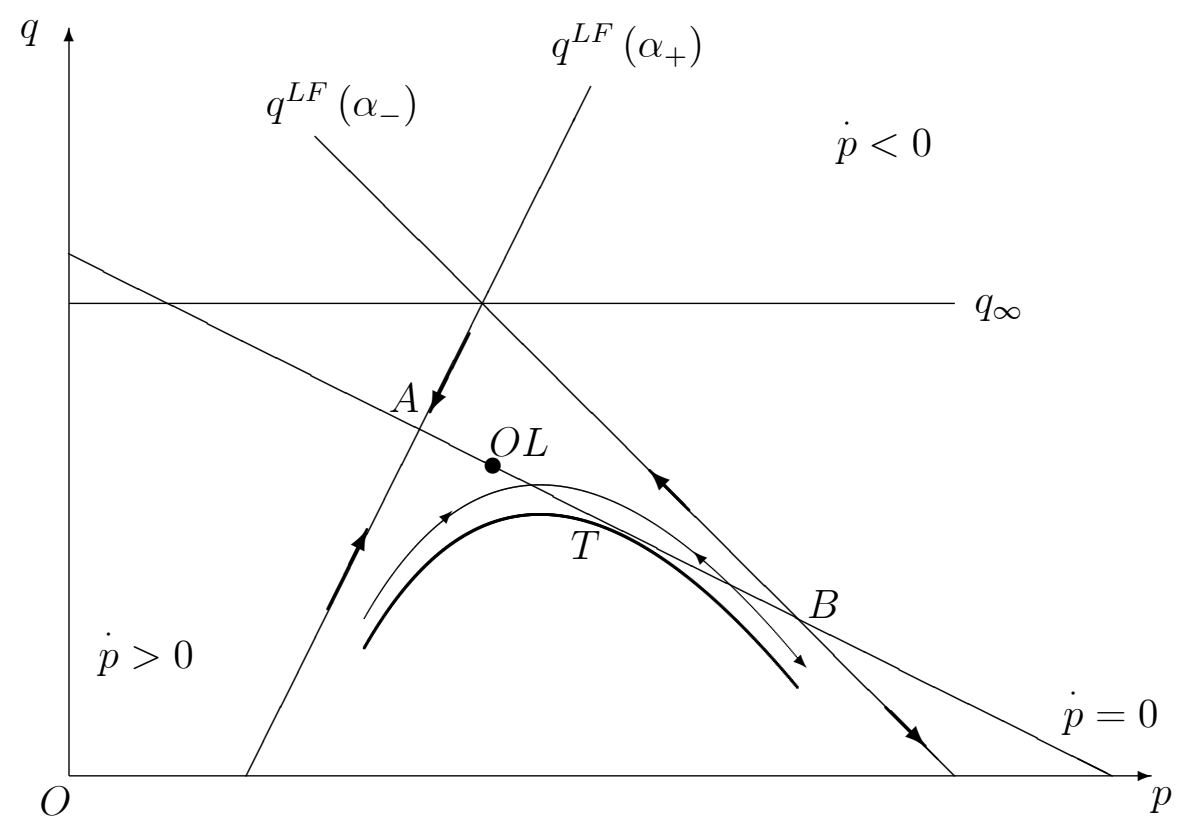

A last remark to which we will return in the remainder. The bullet along $\dot{p}=0$ identifies the open-loop steady state point. As already noted by Tsutsui and Mino (1990), every stable steady state equilibrium (generated by nonlinear feedback strategies) at any point in the open interval between $O L$ and $T$ denotes a collusive outcome, as individual output is below both that associated with the stable feedback equilibrium and that characterising the open-loop one. 


\section{Voluntary export restraint}

Here we assume that firm $f$ adopts a voluntary export restraint by fixing its output at some $q_{f}=\bar{q} \in\left(q_{s s}^{L F}\left(\alpha_{+}\right), q^{T}\right)$ throughout the game. As a result, the home firm solves a problem in which $\bar{q}$ is in fact an additional exogenous constant. Firm $h$ must solve

$$
\rho V_{h}(p)=\max _{q_{h}}\left\{\left(p-c-\frac{q_{h}}{2}\right) q_{h}+V_{h}^{\prime}(p) s\left(a-q_{h}-\bar{q}-p\right)\right\}
$$

To begin with, we characterise the home firm's linear feedback strategies, this time using the method of undetermined coefficients. The first order condition is analogous to (7) and can be solved to obtain

$$
q_{h}=\max \left\{p-c-s V_{h}^{\prime}(p), 0\right\}
$$

For all $c \in\left(0, p-s V_{h}^{\prime}(p)\right)$, substituting $q_{h}=p-c-s V_{h}^{\prime}(p)$ into the above expression and stipulating that $V_{h}(p)=\varepsilon_{1} p^{2}+\varepsilon_{2} p+\varepsilon_{3}$ yields the usual system of three equations to be solved for the coefficients $\varepsilon_{1}, \varepsilon_{2}$ and $\varepsilon_{3}$. This procedure yields:

$$
\begin{gathered}
\varepsilon_{1}^{ \pm}=\frac{4 s+\rho \pm \sqrt{(4 s+\rho)^{2}-4 s^{2}}}{4 s^{2}} \\
\varepsilon_{2}=\frac{c\left(1-2 s \varepsilon_{1}\right)-2 s \varepsilon_{1}(a-\bar{q})}{2 s\left(s \varepsilon_{1}-1\right)-\rho} \\
\varepsilon_{3}=\frac{c\left(c+2 s \varepsilon_{2}\right)+s \varepsilon_{2}\left[2(a-\bar{q})+s \varepsilon_{2}\right]}{2 \rho}
\end{gathered}
$$

The resulting linear feedback strategies can be written as

$$
q_{ \pm}^{L F}=p-c-s\left(2 \varepsilon_{1}^{ \pm}+\varepsilon_{2}\right)
$$

and it can be easily checked that both lead to the same steady state, at which the equilibrium price level is

$$
p_{s s}^{L F}(\bar{q})=\frac{(a-\bar{q})(2 s+\rho)+c(s+\rho)}{3 s+2 \rho}
$$


and intuitively $q_{-}^{L F}=p-c-s\left(2 \varepsilon_{1}^{-}+\varepsilon_{2}\right)$ is stable, while $q_{-}^{L F}$ is unstable. The foregoing discussion proves

Lemma 1 The adoption of a VER by the foreign firm causes the continuum of nonlinear feedback solutions characterising the free trade setting to disappear altogether.

The intuition is elementary: since the competitor's output is fixed, the home firm behaves as a monopolist on the residual demand function, and this intuitively makes the feedback solution unique (at least in a linear-quadratic game), for any given value of $\bar{q}$. As in Dockner and Haug (1991) and Fujiwara (2010), one may as well solve firm h's Hamiltonian. However, this procedure would not illustrate the collapse of the continuum of feedback equilibria shown in Figure 2, in which the two linear feedback strategies intersect the steady state locus at the same point.

Figure 2 The linear feedback strategies of firm $h$ under the VER

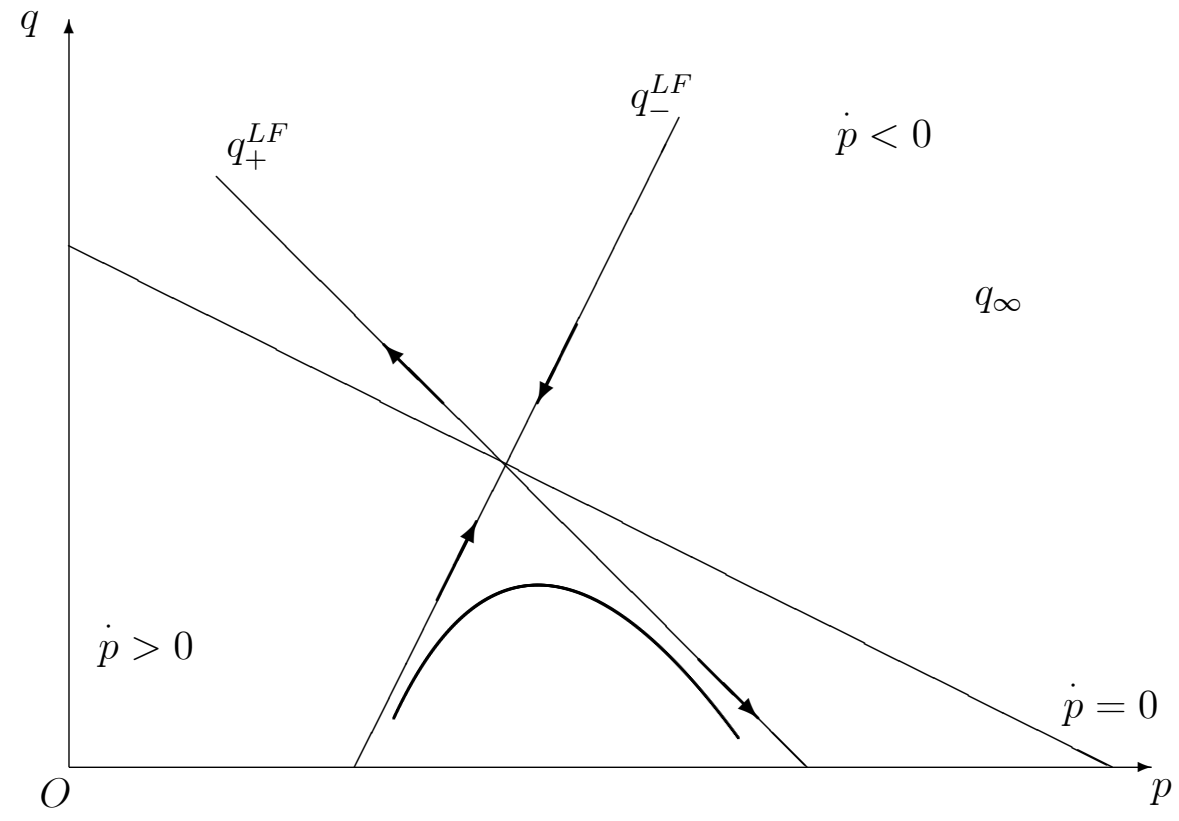


Now we can turn to the parametric analysis of this equilibrium point against the free trade equilibrium described in the previous section. This can be done by noting that $\bar{q}$ is at the same time the VER and the free trade equilibrium output of the home firm, given the full symmetry of the free trade case. Hence, specifying explicitly the nature of $\bar{q}$, which can be written as ${ }^{2}$

$$
\bar{q}=\phi q_{s s}^{L F}\left(\alpha_{+}\right)+(1-\phi) q^{T}, \phi \in(0,1]
$$

one is accounting for all possible output levels which, from $h$ 's standpoint, represent both its free trade quantity and firm $f$ 's VER.

The sign of $q_{-}^{L F}-\bar{q}$ is the sign of the following expression:

$$
\begin{gathered}
-2(4 s+3 \rho)\left(3 s-\rho+\sqrt{(6 s+\rho)^{2}-12 s^{2}}\right) \phi+ \\
+3 s\left(8 s+5 \rho+\sqrt{(6 s+\rho)^{2}-12 s^{2}}\right),
\end{gathered}
$$

in which the coefficient of $\phi$ is always negative, as is easily checked. Hence, (30) is positive (negative) for all $\phi$ lower (higher) than

$$
\widehat{\phi}=\frac{3 s\left(8 s+5 \rho+\sqrt{(6 s+\rho)^{2}-12 s^{2}}\right)}{2(4 s+3 \rho)\left(3 s-\rho+\sqrt{(6 s+\rho)^{2}-12 s^{2}}\right)} \in(0,1),
$$

for all $s, \rho>0$.

Therefore, we may formulate our main result as follows:

Proposition 2 For all $\phi \in(0, \widehat{\phi}), q_{-}^{L F}>\bar{q}$, while for all $\phi \in(\widehat{\phi}, 1]$, $q_{-}^{L F}<\bar{q}$.

The above Proposition says that if the free trade equilibrium output and the corresponding VER are sufficiently close to the output associated with

\footnotetext{
${ }^{2}$ The assumption $\phi \in(0,1]$ is explicitly meant to exclude the quantity associated with the tangency point, as the latter is unstable.
} 
the tangency solution, then the response of firm $h$ to firm $f$ 's adoption of a VER consists in producing more than at the initial free trade equilibrium (and therefore also more than the VER). If instead the free trade equilibrium output and the VER are sufficiently close to the output associated with the stable linear feedback strategy, the opposite holds.

Taking into account the stable linear feedback solution in the limit as $s \rightarrow \infty$, Dockner and Haug (1991) find out that if firm $f$ adopts a VER at the free trade level, this causes a decrease in industry output through a decrease in the production of the home firm and a corresponding increase in the equilibrium price. The ultimate consequence of this mechanism is a profit increase accruing to the foreign firm, motivating the voluntary adoption of the VER by the latter. What Fujiwara (2010) adds to the picture is that this holds for the linear feedback solution for any speed of price adjustment, while it does not apply in the tangency point under nonlinear feedback strategies. However, one should note that this nonlinear solution is unstable (indeed, it is one of the boundaries of a set including infinitely many unstable nonlinear solutions).

What we have found here is that, given the continuum of stable feedback equilibria characterising the free trade scenario, the same conclusion reached by Dockner and Haug (1991) emerges in infinitely many cases. Yet, the opposite holds true as well, since for all $\phi \in(0, \widehat{\phi})$, the fact that $q_{-}^{L F}>\bar{q}$ means that firm $f$ floods the market as a reaction to the VER. This induces a decrease in price and in firm $f$ 's profits, and therefore the foreign firm has no incentive to tie its hands to a VER.

In particular, note that in correspondence of $\widehat{\phi}$,

$$
\bar{q}=q^{O L}=\frac{(a-c)(s+\rho)}{4 s+3 \rho}
$$

showing that the reversal of fortunes takes place in correspondence of the open-loop output, which can be attained through the adoption of a specific nonlinear feedback strategy, as we know from the previous Section. This reveals that Fujiwara's (2010) finding, according to which the VER has no 
effects at all under open-loop rules, can be interpreted anew to say that the absence of precommitment cannot be deemed as the driver of the spontaneous adoption of a VER. Accordingly, we may reformulate the result spelled out in Proposition 2 in a more explicit way:

Proposition 3 For all $\bar{q} \in\left(q^{T}, q^{O L}\right), q_{-}^{L F}>\bar{q}$ and this prevents the adoption of the VER at $\bar{q}$. Instead, for all $\bar{q} \in\left(q^{O L}, q_{s s}^{L F}\left(\alpha_{+}\right)\right], q_{-}^{L F}<\bar{q}$ and this prompts the adoption of the VER at the free trade level by the foreign firm.

The consequences on firms' profits are intuitive: in the range in which firm $f$ voluntarily adopts the export restriction at the free trade level, i.e., for all $\phi \in(\widehat{\phi}, 1]$, the combined effect of industry output reduction and domestic price reduction makes both firms better off as compared to the initial free trade equilibrium, irrespective of the speed of price adjustment:

Corollary 4 For all $\bar{q} \in\left(q^{O L}, q_{s s}^{L F}\left(\alpha_{+}\right)\right]$and all $s \in[0, \infty)$, the adoption of a VER by the foreign firm also benefits the domestic one.

To complete the analysis, we may now briefly assess the impact of the VER on social welfare in the two countries. As for country $f$, welfare coincides with its firm's profits, and therefore obviously the adoption of the VER is welcome whenever it is spontaneously adopted by the exporting firm itself. This amounts to saying that, as far as country $f$ is concerned, private and social incentives are systematically aligned.

When it comes to the welfare consequences in country $h$, one has to keep in mind that for all $\phi \in(\widehat{\phi}, 1]$, the steady state industry output associated with the VER becomes lower than that purchased by consumers in country $h$ at the symmetric free trade steady state equilibrium. The resulting decrease in domestic consumer surplus more than offsets the increase in the domestic firm's profits and consequently steady state welfare in the home country is diminished by the adoption of the VER. ${ }^{3}$

\footnotetext{
${ }^{3}$ The detailed calculations are omitted for brevity as they can be easily reproduced using the expressions of the relevant steady state quantities.
} 
At first sight, these considerations may indeed seem pretty obvious. Yet, they have some relevant bearings on the interpretation of the prediction yielded by the static version of the Cournot game in Mai and Hwang (1988). Consider the special case in which $\phi=\widehat{\phi}$. Here, the industry reaches a steady state through either open-loop strategies or a specific nonlinear feedback one, in such a way that (i) the two steady states are observationally equivalent, and (ii) the domestic firm's best reply to the VER is the VER itself. Moreover, from Fershtman and Kamien (1987), we know that the limit of the open-loop equilibrium as either $\rho \rightarrow 0$ or $s \rightarrow \infty$ is the static equilibrium. Therefore, we see that Mai and Hwang's (1988) irrelevance result is a very special case (indeed, the limit with no discounting or instantaneous price adjustment) of the open-loop scenario. Indeed, the static analysis (Harris, 1985; Mai and Hwang, 1988) holds that a VER cannot be expected to emerge under quantity competition (conjectural variations being nil) while one should expect exporting firms to adopt it under price competition (conjectural variations being negative). In line with Dockner (1987), one may rather say that, in a quantity-setting differential game, a VER can be adopted if competition generated by feedback rules is at least as harsh as under open-loop ones. In such cases (in the present model, for any $\phi \in(\widehat{\phi}, 1])$, the negativity of conjectural variations goes along with output expansion and generates a decrease in price analogous to what we are used to observe if firms do compete in prices.

A few additional words suffice to appreciate what happens for all $\phi \in$ $(0, \widehat{\phi})$. In this range, firm $f$ has no incentive to adopt a VER, which is often labelled as 'involuntary'. This attribute is misleading, as the foreign firm just does not use the VER. If it did, then domestic welfare and consumer surplus would increase as compared to the free trade level because of the output expansion by the home firm, while the effect on the profits of the latter is ambiguous and depends on the relative size of $s$ and $\rho .{ }^{4}$

\footnotetext{
${ }^{4} \mathrm{~A}$ static model in which the voluntary restriction on exports makes all subjects better off is in Syropoulos (1996), where the domestic firm's profit increase more than compen-
} 


\section{Concluding remarks}

We have generalised the analysis initiated by Dockner and Haug (1991) and extended by Fujiwara (2010), on the adoption of VERs in the differential game of intraindustry trade with Cournot behaviour and sticky price dating back to Simaan and Takayama (1978) and Fershtman and Kamien (1987). Our approach was meant to point out that the rationale for the VER can be found in the intensity of competition under feedback rules, which delivers an effect equivalent to that usually associated with price competition, in such a way that one can interpret the adoption of a VER on the basis of conjectural variations (Dockner, 1992).

As a final remark, we would like to mention that, along the parallel stream of research dealing with the equivalence between tariffs and quotas there also appeared a few contributions investigating this issue in differential games (Dockner and Haug, 1990; Calzolari and Lambertini, 2006; and Yanase, 2007). The extension of these efforts to account for the whole spectrum of feedback solutions, which may well deliver new insights on a long-standing issue, is a desirable direction for future research.

sates the decrease in domestic consumer surplus. 


\section{References}

[1] Bhagwati, J. (1965), "On the Equivalence of Tariffs and Quotas", in R. Baldwin et al. (eds), Trade, Growth, and the Balance of Payments. Essays in Honor of Gottfried Haberler, Chicago, Rand McNally.

[2] Bjorksten, N. (1994), "Voluntary Import Expansions and Voluntary Export Restraints in an Oligopoly Model with Capacity Constraints", Canadian Journal of Economics, 27, 446-57.

[3] Bresnahan, T. (1981), "Duopoly Models with Consistent Conjectures", American Economic Review, 71, 934-45.

[4] Calzolari, G. and L. Lambertini (2006), "Tariffs vs Quotas in a Trade Model with Capital Accumulation", Review of International Economics, 14, 632-44.

[5] Calzolari, G. and L. Lambertini (2007), "Export Restraints in a Model of Trade with Capital Accumulation", Journal of Economic Dynamics and Control, 31, 3822-42.

[6] Dockner, E.J. (1992), "A Dynamic Theory of Conjectural Variations", Journal of Industrial Economics, 40, 377-95.

[7] Dockner, E. and A. Haug (1990), "Tariffs and Quotas under Dynamic Duopolistic Competition", Journal of International Economics, 29, 147 59.

[8] Dockner, E. and A. Haug (1991), "The Closed Loop Motive for Voluntary Export Restraints", Canadian Journal of Economics, 3, 679-85.

[9] Dockner, E. and N.V. Long (1993), "International Pollution Control: Cooperative versus Noncooperative Strategies", Journal of Environmental. Economics and Management, 24, 13-29. 
[10] Eaton, J. and G.M. Grossman (1986), "Optimal Trade and Industrial Policy under Oligopoly", Quarterly Journal of Economics, 101, 383-406.

[11] Fershtman, C. and M. Kamien (1987), "Dynamic Duopolistic Competition with Sticky Prices", Econometrica, 55, 1151-64.

[12] Fujiwara, K. (2008), "Duopoly Can Be More Anti-Competitive than Monopoly", Economics Letters, 101, 217-19.

[13] Fujiwara, K. (2010), "When Are Voluntary Export Restraints Voluntary? A Differential Game Approach", Australian Economic Papers, 49, 101-10.

[14] Harris, R. (1985), "Why Voluntary Export Restraints Are 'Voluntary", Canadian Journal of Economics, 18, 799-809.

[15] Hwang, H. and C.-C. Mai (1988), "On the Equivalence of Tariffs and Quotas under Duopoly", Journal of International Economics, 24, 37380 .

[16] Itoh, M. and Y. Ono (1982), "Tariffs, Quotas and Market Structure", Quarterly Journal of Economics, 97, 295-305.

[17] Itoh, M. and Y. Ono (1984), "Tariffs vs Quotas under Duopoly of Heterogeneous Goods", Journal of International Economics, 17, 359-73.

[18] Kamien, M. and N Schwartz (1983), "Conjectural variations", Canadian Journal of Economics, 16, 191-211.

[19] Krishna, K. (1989), "Trade Restrictions as Facilitating Practices", Journal of International Economics, 26, 251-70.

[20] Lambertini, L. (2016), "Managerial Delegation in a Dynamic Renewable Resource Oligopoly", in H. Dawid, K. Doerner, G. Feichtinger, P. Kort and A. Seidl (eds), Dynamic Perspectives on Managerial Decision Making: Essays in Honor of Richard F. Hartl, Heidelberg, Springer. 
[21] Lambertini, L. and Mantovani, A. (2014), "Feedback Equilibria in a Dynamic Renewable Resource Oligopoly: Pre-emption, Voracity and Exhaustion", Journal of Economic Dynamics and Control, 47, 115-22.

[22] Lambertini, L. and A. Mantovani (2016), "On the (In)stability of Nonlinear Feedback Solutions in a Dynamic Duopoly with Renewable Resource Exploitation", Economics Letters, 143, 9-12.

[23] Mai, C. and H. Hwang (1988), "Why Voluntary Export Restraints Are Voluntary: An Extension", Canadian Journal of Economics, 21, 877-82.

[24] Rowat, C. (2007), "Non-linear Strategies in a Linear Quadratic Differential Game", Journal of Economic Dynamics and Control, 31, 3179-202.

[25] Shibata, H. (1968), "A Note on the Equivalence of Tariffs and Quotas", American Economic Review, 58, 137-42.

[26] Shimomura, K. (1991), "Feedback Equilibria of a Differential Game of Capitalism", Journal of Economic Dynamics and Control, 5, 317-38.

[27] Simaan, M. and T. Takayama (1978), "Game Theory Applied to Dynamic Duopoly Problems with Production Constraints", Automatica, 14, 161-66.

[28] Suzumura, K. and J. Ishikawa (1997), "Voluntary Export Restraints and Economic Welfare", Japanese Economic Review, 48, 176-86.

[29] Syropoulos, C. (1996), "On Pareto-improving Voluntary Export Restraints", International Journal of Industrial Organization, 14, 71-84.

[30] Tsutsui, S. and K. Mino (1990), "Nonlinear Strategies in Dynamic Duopolistic Competition with Sticky Prices", Journal of Economic Theory, 52, 136-61.

[31] Yanase, A. (2007), "Dynamic Games of Environmental Policy in a Global Economy: Taxes versus Quotas", Review of International Economics, 15, 592-611. 


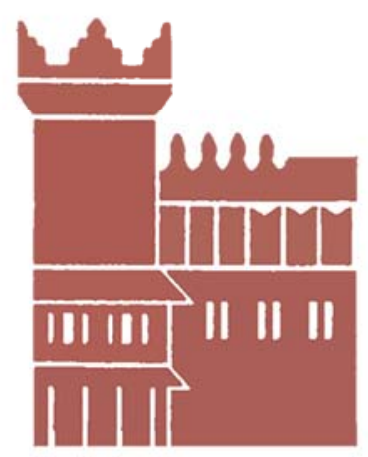

Alma Mater Studiorum - Università di Bologna DEPARTMENT OF ECONOMICS

Strada Maggiore 45

40125 Bologna - Italy

Tel. +39051 2092604

Fax +390512092664

http://www.dse.unibo.it 